\title{
Corpo, utopia e limite no pensamento de Michel Foucault
}

\author{
Mauricio Silva, ${ }^{\mathbb{D}} \star$ Reinaldo Furlan \\ Universidade de São Paulo, Ribeirão Preto, SP, Brasil
}

Resumo

\begin{abstract}
Este artigo discute a relação entre corpo e limite na obra de Michel Foucault, notadamente em textos que figuram às margens de sua interpretação canônica. A discussão sobre o corpo está presente em diversos momentos de sua obra e ganha destaque no final da década de 1970, quando a análise dos processos de subjetivação predomina em seu pensamento. A noção de limite, por sua vez, pode ser compreendida de diferentes maneiras dentro de sua obra. Em nossa análise, trataremos da utilização especifica do termo "experiência-limite" em dois textos fora do "cânone", confrontando-os com uma das abordagens mais diretas sobre o corpo que pode ser encontrada na obra foucaultiana: a rádioconferência $\mathrm{O}$ corpo utópico, de 1966.
\end{abstract}

Palavras-chave: Foucault; corpo; limite; utopia; subjetividade.

\section{Body, utopia and limit in Foucault's thought}

\begin{abstract}
This paper discusses the relation between body and limit in some texts from Michel Foucault's work, especially those that appear on the margins of its canonical interpretation. The discussion about body is present in many moments of his work, and becomes an important element, especially in the analysis of the processes of subjectivity that prevailed in his thought at the end of the 1970's. The notion of limit, in turn, can be understood in different ways in his work. In our approach, we will discuss the specific use of the term "limit-experience" in two texts that appears out of the canon, confronting them with one of the most direct approaches on body that can be found in Foucault's work: a radio conference called Utopian body, issued in 1966.
\end{abstract}

Keywords: Foucault; body; limit; utopia; subjectivity.

\section{Introdução}

Confrontar um limite significa explorar um lado de fora de uma experiência possível; até por isso, a experiência-limite pode ser compreendida como uma "experiência do fora"1 (FOUCAULT, 1966/1994, p. 520; 522; $523 ; 537)$. Se nos ampararmos no diagrama deleuziano sobre Foucault, veremos que esse fora não se confunde com uma simples exterioridade, trata-se antes de "forças em relação com outras forças” (DELEUZE, 1988, p. 94). Forças móveis, ainda não formadas para a composição de uma figura de experiência. Segundo o próprio Foucault (2001, p. 862, tradução nossa), a "ideia de uma experiência-limite, que arranca o sujeito de si mesmo", sempre foi projetada em seus livros. Nesse sentido, é possível encontrar a ideia de uma "experiência-limite" em momentos distintos de sua obra. Em História da loucura na idade clássica, por exemplo, Foucault (1961/1978) mostra como, entre os séculos XVII e XIX, surge um movimento social na Europa, coincidente com a ascensão e consolidação de uma classe econômica burguesa, que buscava controlar a manifestação social da diferença, sobretudo por meio de práticas coercitivas a respeito da loucura, em termos específicos, representado pela criação de um "hospital geral" na França no final do século XVII. Na referida obra, a ideia de uma experiência-limite não está presente somente no modus operandi fou-

\footnotetext{
^Endereço para correspondência: Universidade de São Paulo, Faculdade de Filosofia Ciências e Letras de Ribeirão Preto. Av. Bandeirantes, 3900, Vila Monte Alegre - Ribeirão Preto, SP - Brasil. CEP: 14040-901. E-mails: mauriciojrs@ bol.com.br, reinaldof@ffclrp.usp.br

Os dados completos dos autores encontram-se ao final do artigo

É importante informar que o termo dehors, presente nos textos de Foucault de 1963, 1966 e na entrevista de 1978, também pode ser encontrado, traduzido para a língua portuguesa, como "exterior". Para o presente artigo, optou-se pela tradução de dehors como "fora", até para que o leitor não relacionasse o termo dehors a uma mera exterioridade subjetiva.
}

caultiano, ou seja, no movimento teórico-metodológico de historicizar a loucura. Como afirma Foucault (2001, p. 863), seu "problema não era satisfazer historiadores profissionais", mas problematizar a si mesmo e "convidar os outros", seus interlocutores, a fazerem o mesmo. Para o autor, mais do que um simples movimento de análise, esse livro "funciona como uma experiência", tanto para "aquele que escreve" quanto para "aquele que lê", pois, mais que descrever o movimento histórico de constituição da verdade, a obra, "em certo ponto, a destrói" (FOUCAULT, 2001, p. 864, tradução nossa). Se na obra de 1961 Foucault (2001, p. 863, tradução nossa) mostra como a verdade acerca da loucura é atravessada por "conteúdos históricos determinados", catorze anos depois, em Vigiar e Punir (FOUCAULT, 1975/2008), o autor estabelece um novo objeto de enfrentamento: as prisões. Embora durante esse período Foucault tenha produzido diferentes obras e utilizado metodologias de análise distintas, o movimento de análise que propiciava um questionamento da própria subjetividade ainda estava presente. Quando questionado se a relação com a verdade, presente em História da loucura na idade clássica (FOUCAULT, 1961/1978), se repetira em obras seguintes, Foucault (2001, p. 864-865, tradução nossa) afirmou:

Poderíamos dizer a mesma coisa a respeito de Vigiar e $\mathrm{Pu}$ nir... O livro faz uso de documentos verdadeiros, mas de modo que através deles seja possível efetuar não somente uma constatação da verdade, mas também uma experiência que autoriza uma alteração, uma transformação na relação que temos com nós-mesmos e com o mundo.

Essa experiência de "transformação... de nós-mesmos" é, na verdade, o que Foucault $(2001$, p. 864, 862) chama de "experiência-limite". Na obra de 1975, Foucault dá continuidade à prevalência metodológica dos 
"conteúdos históricos" na problematização de seus objetos de análise. Se em 1961 seu objeto era a loucura, em 1975 ele volta sua atenção para a emergência histórica das prisões. O livro, aliás, inicia-se com a descrição do corpo de um supliciado na segunda metade século XVIII (FOUCAULT, 2008). Ao percorrer temas como suplício, punição, disciplina e prisão, o autor mostra como a crítica ao suplício e à humanização moderna da pena possibilitaram a criação de estratégias distintas de atuação do poder, que passam tanto pelo disciplinamento dos corpos quanto pelo aprimoramento das técnicas de vigilância. Como citado no excerto, a experiência-limite que a obra em questão suscita está na possibilidade de resistir a discursos e práticas, surgidos na modernidade, que tratam da "instituição de repressão, de eliminação, de exclusão, de marginalização", e que são derivados de "múltiplos dispositivos de encarceramento" e controle (FOUCAULT, 2008, p. 254). É importante ressaltar que, nesse caso, resistir não significa propriamente "apresentar-se" contra um alvo central e suas ramificações de poder na sociedade, em alusão à abordagem clássica do marxismo, mas atuar na constituição de pequenas "dissidências" que integram os jogos de poderes. Como esses jogos atuam diretamente sobre os corpos e sobre as relações de saber-poder atinentes a estes, é também nos corpos que a resistência a esse poder ocorrerá. Ou seja, como o governo é antes efeito a práticas de governabilidade, presentes no cotidiano do cidadão comum, e em particular nas instituições políticas da sociedade, no sentido estrito do termo, é para a imanência das relações de poder que nos endereça o pensamento de Foucault. Essa ideia de "arrancar o sujeito de si mesmo" é tão importante dentro do pensamento foucaultiano que, mesmo em uma obra como Doença mental e personalidade (1954), "obra totalmente desconexa de tudo que [Foucault] produziu posteriormente" (FOUCAULT, 2001, p. 1484, tradução nossa), ainda assim tal perspectiva limite pode ser encontrada. Na versão de $1962^{2}$ da referida obra, intitulada Doença mental e psicologia, apesar de Foucault $(1962,1975)$ mostrar como se dá a constituição do corpo como objeto de saber, ele toma a linguagem do louco como um ponto de reflexão filosófica, não para explicá-la ou para corrigi-la, mas para utilizá-la como um elemento de transgressão ao discurso científico-racional (FOUCAULT, 1975, p. 61; $64 ; 67 ; 69)$. Malgrado a obra de $1954^{3}$ e sua versão de

${ }^{2}$ A obra Doença mental e psicologia, publicada em 1962, é uma releitura da obra Doença mental e personalidade, publicada em 1954, na qual Foucault discute a constituição da patologia mental. Embora possuam algumas linhas argumentativas semelhantes, as obras se diferem principalmente em constituição teórica e conclusão. Sob a influência de algumas abordagens fenomenológicas, na obra de 1954, Foucault analisa a constituição da patologia mental sob um enfoque antropológico. Já na obra de 1962, a patologia mental é analisada principalmente sob um enfoque histórico, ou seja, sua raiz não está dada no homem, propriamente dito, mas em uma relação "historicamente situada, entre o homem, o homem louco e o homem verdadeiro" (FOUCAULT, 1975, p. 5).

${ }^{3}$ Em entrevista concedida a J. François e J. de Wit em 22 de maio de 1981, Foucault (2001) afirma que Doença mental e personalidade (1954) foi escrita em um momento no qual "as diferentes significações da palavra alienação, seu sentido sociológico, histórico e psiquiátrico, se confundiam com uma perspectiva fenomenológica, marxista e psiquiátrica". Diante desse contexto, a obra de 1954 é uma tentativa de apontar um problema que não foi resolvido naquele momento, nem posteriormente. Nas obras que se seguiram, não houve uma tentativa de relacionar "Hegel e a psiquiatria, passando pelo neomarxismo", mas compreender a loucura "do ponto de vista histórico". Feitas essas ressalvas, Foucault (2001) diz, ainda, que embora seu primeiro texto sobre a doença mental seja coerente em si, ele não está relacionado com seus textos seguintes (FOUCAULT, 2001, p. 1484, tradução nossa).
$1962^{4}$, em geral, não sejam consideradas pelos comentadores de Foucault como predecessoras do método arqueológico que viria a ser desenvolvido por Foucault nos anos seguintes, ainda assim essa obra, sobretudo a versão de 1962, pode ser considerada como um modelo discursivo interessante dentro do pensamento foucaultiano para se analisar a relação entre loucura e limite. Isso se dá porque, neste caso, a linguagem do louco não é utilizada como uma via científica para a constituição de métodos de cura ou procedimentos de diagnóstico, mas como forma de superar uma possível dicotomia entre razão e desrazão (FOUCAULT, 1975, p. 60).

Se, em termos gerais, a ideia de uma experiência do fora, "de arrancar o sujeito de si mesmo" (FOUCAULT, 2001, p. 862), é recorrente em diferentes momentos de sua obra, ao contrário, a utilização específica do termo “experiência-limite" não é tão recorrente. Em nossa pesquisa, encontramos duas exposições mais diretas do termo: a primeira de 1963, presente no artigo "Prefácio à transgressão" (FOUCAULT, 1963/1994), publicado na Revista Critique número 195-196; a segunda, contida em uma entrevista concedida a Dúcio Trombadori em 1978, publicada na primeira edição da Revista Il Contributo, de janeiro-março de 1980, e também presente no segundo volume da edição francesa da coletânea Dits et Ecrits II (FOUCAULT, 1994/2001).

Na entrevista de 1978, Foucault (2001) discute alguns temas relativos à experiência da loucura, presentes em suas primeiras obras, e algumas questões relativas ao poder e à vontade de saber, presentes no primeiro volume de História da Sexualidade (FOUCAULT, 1976/1999). Ao ser questionado sobre como reage diante de certos analistas que tentam enquadrar seu pensamento em determinada corrente filosófica, Foucault (1994/2001, p. 861-862) é taxativo:

Não me considero um filósofo... Os autores mais importantes, não diria para minha formação, mas que permitiram que eu me deslocasse em relação à minha formação universitária, foram pessoas como Bataille, Nietzsche, Blanchot, Klossowski, que não eram filósofos, no sentido institucional do termo, e um certo número de experiências pessoais, seguramente. O que mais me tocou e fascinou nesses autores, e que lhes deram essa importância capital para mim, é que a questão deles não era a construção de um sistema, mas de uma experiência pessoal. Na universidade, ao contrário, eu havia sido treinado, formado, levado à aprendizagem dessas grandes maquinarias filosóficas que se chamavam hegelianismo, fenomenologia... (tradução nossa).

Após o autor afirmar seu interesse por essa “experiência pessoal", o entrevistador o questiona a respeito de uma possível aproximação com a Fenomenologia, e é neste trecho que Foucault (1994/2001, p. 862) cita o que entende por experiência-limite:

A experiência fenomenológica é, no fundo, uma certa maneira de pôr um olhar reflexivo sobre um objeto qualquer do vivido, sobre o cotidiano em sua forma transitória para dele

${ }^{4}$ Por mais que a obra de 1954 e sua revisão de 1962 não estejam relacionadas teoricamente com as obras que se seguem nos anos 60, 70 e 80, acreditamos que é importante citá-la para mostrar que, mesmo em uma obra aparentemente "desconexa" das demais, a ideia de experiência-limite se faz presente. 
apreender as significações. Para Nietzsche, Bataille, Blanchot, ao contrário, a experiência é a tentativa de alcançar certo ponto da vida que seja o mais próximo possível do impossível de viver. O que se requer é o máximo de intensidade e, ao mesmo tempo, de impossibilidade. O trabalho fenomenológico, ao contrário, consiste em desdobrar todo o campo de possibilidades ligadas à experiência cotidiana. Além disso, a fenomenologia busca retomar a significação da experiência cotidiana para reencontrar em que o sujeito que eu sou é efetivamente fundador, em suas funções transcendentais, dessa experiência e dessas significações. Ao contrário, a experiência em Nietzsche, Blanchot, Bataille tem por função arrancar o sujeito de si-mesmo, de alguma forma fazer com que ele não seja mais ele mesmo ou que ele seja levado a sua destruição ou dissolução. É uma proposta de dessubjetivação. A ideia de uma experiência-limite, que arranca o sujeito de si-mesmo, eis o que foi importante para mim na leitura de Nietzsche, Bataille e Blanchot, e que fez com que, por mais chatos ou eruditos que sejam meus livros, eu sempre os concebi como experiências diretas visando me arrancar de mim mesmo, a me impedir de ser o mesmo.

O conceito de limite exposto no excerto coincide com a proposta foucaultiana de uma ontologia histórica, posta na esteira filosófica do "além do homem" de Nietzsche (1885/2011) e da "fuga de si" de George Bataille (1944/1986). Nessa perspectiva, a ideia de limite dá-se antes pela tentativa de ultrapassagem histórica de si do que propriamente pela busca de estruturas gerais da existência. Embora a entrevista de 1978 apresente uma das exposições mais claras acerca da "experiência-limite" que encontramos no pensamento foucaultiano, ela não apresenta a mesma complexidade teórica do texto de 1963, Prefácio à transgressão (FOUCAULT, 1963/1994). O texto de 1963 é, na verdade, uma homenagem póstuma ao escritor francês George Bataille, que havia falecido um ano antes. A fim de suscitar algumas questões presentes no trabalho do escritor, Foucault se vale de quatro temáticas principais: a sexualidade, a transgressão, a religiosidade e a linguagem. Em todas elas a questão da experiência-limite é suscitada.

Evidenciada a importância da noção de experiência-limite dentro do pensamento focaultiano, cumpre-nos realizar um duplo movimento de análise: o primeiro para tentar explicar como Foucault extrai essa experiência do pensamento de George Bataille, mais especificamente de sua obra Experiência Interior, de 1944; e o segundo para analisar essa busca por uma experiência-limite em dois textos que figuram fora de sua "tríade canônica", 5 a saber: duas radioconferências, proferidas no ano de 1966, intituladas Heterotopias e O corpo utópico.

\section{Bataille, o erotismo, a linguagem e a transgressão}

A problematização do limite tem grande importância no pensamento de George Bataille e está presente na obra La Experiência Interior (BATAILLE, 1944/1986, p. 1819), na qual o autor debate com Maurice Blanchot a busca por uma experiência que consiga viajar ao "extremo do possível" no campo da escrita. Essa experiência é enten-

\footnotetext{
Quando utilizamos o termo "tríade canônica" nos referimos a três momentos que, de acordo com alguns analistas, representam os momentos principais da obra foucaultiana, a saber: a arqueologia, a genealogia e a ética.
}

dida por Bataille como uma metamorfose entre aquilo que ele chama de experiência interior e o que Blanchot chama de "experiência-limite" (BATAILLE, 1986, p. 72).

De acordo com a leitura foucaultiana, os dois primeiros pontos nos quais o conceito de experiência-limite se apresenta no pensamento de Bataille são a sexualidade e a religiosidade, ou, nos termos de Bataille (1986, p. 34; 28; 142-143), o "erotismo" e a "morte de Deus". Sobre a sexualidade, Foucault (1963/1994) argumenta que não existe a possibilidade de ela ser liberada. Esse argumento coincide com aquele apresentado no primeiro volume de História de Sexualidade (1976/1999), que contesta a ideia de uma hipótese repressiva acerca da sexualidade. Ora, se não há uma sexualidade pura ou essencial, não haveria por que existir sua liberação. Mas o que há, então? Segundo Foucault (1994), há justamente uma possibilidade limite. Em Bataille (1944/1986) essa possibilidade de um limite para a experiência sexual se relaciona com a "morte de Deus"6 (BATAILLE, 1986, p. $131 ; 136 ; 139 ; 143)$. A temática da morte de Deus já foi explorada por Nietzsche (1882/2006) em sua obra A gaia ciência. Segundo o filósofo alemão, a morte de Deus coincide com a emergência de um pensamento racional, principalmente na Europa oitocentista, que converte diversas atitudes do cotidiano de práticas religiosas (sagrado) em práticas pautadas pelo saber científico. De acordo com Nietzsche (1882/2006, p. 129): "Deus morreu! Deus continua morto! E fomos nós que o matamos". Diante dessa perspectiva, Bataille (1944/1986) compreende que a morte de Deus no mundo moderno implica a retirada de um limite para a existência humana, mais precisamente, possibilita a compreensão de sua expressão fundamental. É desse modo que a sexualidade, por meio da experiência do erotismo, ${ }^{7}$ surge como a experiência que se "faz e desfaz no excesso que transgride" (FOUCAULT, 1994, p. 236, tradução nossa). Essa expressão ("possibilidade limite") utilizada por Foucault (1994/2001) para descrever uma experiência-limite a partir da convergência do erotismo (experiência da sexualidade) com a morte de Deus suscita, pois, um segundo tema que é muito importante quando se trata de uma experiência-limite em Bataille: a transgressão. É ela que "leva o limite até o limite de seu ser", é também ela que faz o sujeito "experimentar a verdade positiva no movimento da perda, ou ainda no movimento de pura violência" (FOUCAULT, 1963/1994, p. 237, tradução nossa). Logo, ela é compreendida por Foucault (1994/2001) como uma atitude de ultrapassagem de uma linha muito tênue que leva o "ser" ao limite. Há nessa interpretação alguns pontos que convergem com a abordagem foucaultiana, expressa na entrevista de 1978, e outros que não operam do mesmo modo. $\mathrm{Na}$

\footnotetext{
6“[...] Se é preciso que o homem chegue até seu extremo, que sua razão desfaleça, que Deus morra, nem as palavras, nem seus jogos mais doentios possam bastar" (BATAILLE, 1986, p. 143, tradução nossa).

A questão do erotismo como possibilidade limite é tão importante para Bataille (1986) nessa obra que sua última parte é intitulada "nudez". No primeiro parágrafo que inicia essa parte, o autor deixa isso bem evidente: "No final das contas, tudo me coloca em jogo, permaneço suspenso, nu, em uma solidão definitiva: ante a impenetrável simplicidade do que é; e uma vez aberto o fundo dos mundos, o que vejo e o que sei já não tem sentido nem limites, e não pararei até que não tenha avançado ao mais longe que eu possa" (BATAILLE, 1986, p. 201, tradução nossa).
} 
verdade, a convergência nos parece profunda com toda a obra de Foucault, sob a ótica de que o movimento de seu pensamento, de modo geral, lançou-se contra os limites da linguagem e da experiência de mundo. O que ele fez, justamente, estudando-os em suas estruturas organizadoras de possibilidade dessas experiências, estruturas empírico-transcendentais (FOUCAULT, 1966/2000) formadas através de práticas discursivas e não discursivas. A dissonância, no entanto, aparece porque, em Prefácio à Transgressão (1963/1994), a sexualidade aparece como o fenômeno, por excelência, capaz de expressar a experiência da finitude humana, em particular da linguagem. O que a sexualidade traz à expressão, conforme Foucault (1963/1994, p. 237) indica no prefácio, é o "ser da linguagem”. E sabemos que a sexualidade não terá a mesma sorte ou prerrogativa na História da Sexualidade I (FOUCAULT, 1976/1999), ainda que outra lhe seja atribuída, enquanto dispositivo do bio-poder. ${ }^{8} \mathrm{Ou}$ seja, a prerrogativa passa de positiva a negativa, do elogio à crítica, de um fenômeno capaz de suscitar os limites do ser a uma forma de poder que limita a vida (FOUCAULT, 1976/1999).

A reflexão de Foucault (1963/1994) sobre a linguagem como experiência-limite nos ajuda a compreender isso melhor. Segundo Foucault (1966/2010), a linguagem para Bataille não tem como função "recompor uma experiência perdida", mas produzir uma linguagem não dialética. Em Aristóteles, a dialética, ou a arte das confrontações, pode ser entendida como um procedimento lógico-formal que busca discutir e confrontar opiniões, a fim de instaurar uma verdade. Na abordagem crítica kantiana, a dialética deixa de ser o caminho lógico para a verdade, para integrar um projeto transcendental de investigação de suas possibilidades e limites. Dessa forma, a dialética está presente na própria natureza da razão e não visa somente atuar negativamente como uma contraprova em suas confrontações, mas de forma positiva na sistematização do fenômeno da experiência de mundo, isto é, de seus limites. De acordo com Foucault (1966/2010, p. 758), implicada em uma reflexão crítica sobre a experiência da finitude, a abordagem kantiana, por meio de sua reflexão sobre os limites da razão, promoveu uma "abertura" na reflexão sobre o ser da linguagem, essa mesma que posteriormente deu início e ficou conhecida como a "girada linguística" na filosofia. No caso específico, diante dessas abordagens clássicas da dialética, a linguagem para Bataille não busca aceder a uma verdade, tampouco integrar um projeto da razão, seu valor está posto em "experiência positiva" que busca suscitar a diferença, seja nos diferentes níveis de fala, seja no entendimento da filosofia como um labirinto de ideias. Trata-se de entender o desvio da linguagem ou do pensamento não como uma contradição, como faz a dialética, mas como um ato transgressivo (BIMBENET,

\footnotetext{
${ }^{8} \mathrm{O}$ bio-poder é uma forma de poder "voltada para os desempenhos dos corpos e encarando os processos da vida - caracteriza o poder cuja função mais elevada já não é mais matar, mas investir sobre a vida" (FOUCAULT, 1999, p. 152).

9 “"Chamo de experiência uma viagem até o limite do possível para o homem. Cada um pode não fazer essa viagem, mas, se a faz, isto supõe que nega as autoridades e os valores existentes, que limitam o possível. Pelo fato de ser negação de outros valores, a experiência tem existência positiva, chega para ser ela mesma o valor e a autoridade" (BATAILLE, 1944/1986, p. 17, tradução nossa).
}

2011, p. 24). Em outros termos, é, pois, contra os seus limites que a linguagem se joga, e é desta maneira que a linguagem se apresenta como uma "abertura no ser" (FOUCAULT, 1963/1994, p. 243); abertura não para uma essência recôndita, mas como diferença; tampouco de um ser soberano, mas de um ser fora de si: eis a verdade da diferença, da transgressão e do limite.

Diante dessa exposição foucaultiana da experiência-limite, o problema que se apresenta é como perceber esse movimento de transgressão, esse "arrancar-se de si" (FOUCAULT, 2001, p. 862) diante de um processo histórico que faz justamente o contrário, isto é, que dá forma aos sujeitos e idealiza seus corpos. É essa questão que discutiremos a seguir.

\section{O corpo, a dobra e o limite}

A resposta foucaultiana para a questão acima pode ser encontrada em um texto, em geral pouco explorado por comentadores de Foucault, que apresenta uma interessante reflexão de como o corpo pode suscitar uma "experiência do fora". Trata-se do texto $O$ corpo utópico (FOUCAULT, 1966/2010). Contemporâneo à obra $A s$ palavras e as coisas (FOUCAULT ,1966/2000), o texto foi extraído de um conjunto de duas conferências emitidas nos dias 7 e 21 de dezembro de 1966, no programa Culture française de Robert Valette, na rádio France Culture. Essas conferências são parte de uma série intitulada L'Utopie et la Littérature. Em sua apresentação, elas foram abordadas como "As utopias reais ou lugares e outros lugares" e ainda como "ensaios literários de Michel Foucault” (SABOT, 2012). Dado seu caráter ensaístico, as conferências não necessariamente reproduzem a mesma perspectiva teórica apresentada por Foucault (1966/2000) em As palavras e as coisas, qual seja a constituição de uma espécie de estruturalismo regional (histórico) pautado pelo questionamento do lugar do homem como figura do pensamento. ${ }^{10}$ Em outros termos, as conferências fazem alusão antes à constituição de espaços de diferença e de limite dados a partir do espaço e do corpo, do que propriamente a uma constituição sistêmica pautada por epistemes ${ }^{11}$ e figuras histórico-discursivas.

A primeira das duas conferências, intitulada $\mathrm{He}$ terotopias (FOUCAULT, 1966/2013, p. 21), trata da constituição de ambientes arquitetônicos chamados por Foucault de "espaços absolutamente outros". Esses ambientes, que, segundo o autor, podem ser encontrados nas cidades modernas, se caracterizam como "lugares reais", que suscitam a diferença, a transgressão e, por isso, po-

\footnotetext{
10 "O homem é uma invenção cuja recente data a arqueologia de nosso pensamento mostra facilmente. [...] se, por algum acontecimento de que podemos quando muito pressentir a possibilidade, mas de que no momento não conhecemos ainda nem a forma nem a promessa, se desvanecessem, como aconteceu, na curva do século XVIII, com o solo do pensamento clássico - então se pode apostar que o homem se desvaneceria, como, na orla do mar, um rosto de areia" (FOUCAULT, 2000, p. 535).

11 "Por episteme entende-se, na verdade, o conjunto das relações que podem unir, em uma dada época, as práticas discursivas que dão lugar a figuras epistemológicas, a ciências, eventualmente a sistemas formalizados; o modo segundo o qual, em cada uma dessas formações discursivas, se situam e se realizam as passagens à epistemologização, à cientificidade, à formalização; a repartição desses limiares que podem coincidir, ser subordinados uns aos outros, ou estar defasados no tempo; as relações laterais que podem existir entre figuras epistemológicas ou ciências, na medida em que se prendam a práticas discursivas vizinhas mas distintas" (FOUCAULT, 2009a, p. 214).
} 
dem ser também compreendidos como "contraespaços", lugares que possuem a capacidade de remeter o sujeito a outros lugares, "lugares fora de todos os lugares" (FOUCAULT, 1966/2013, p. 20). O termo heterotopia é aqui utilizado em contraposição a um conceito que é de suma importância na segunda conferência: a noção de utopia. Se a heterotopia designa esses "lugares reais" que suscitam outros lugares, a utopia, por sua vez, diz respeito a lugares fundamentais. Se analisarmos a etimologia do termo utopia, chegaremos à palavra grega topos, que significa "lugar", e que é complementada pelo prefixo "u", que, no grego, designa uma "ausência". Portanto, etimologicamente teríamos a ideia de um "não lugar" ou "lugar nenhum" (CHAUÍ, 2008, p. 7). Se relacionarmos esse aspecto linguístico à história da filosofia, veremos que o termo utopia está em geral relacionado a uma ideia de espaço idealizado, projetado, logo, "não presente" ou "não-real", dependendo do discurso filosófico no qual o termo é apropriado. Em Foucault (1966/2010), a noção de utopia, de certo modo, coincide com essa abordagem. Segundo o autor, "as utopias são posicionamentos sem lugar real... que mantêm com o espaço real da sociedade uma relação geral de analogia direta ou inversa. É a própria sociedade aperfeiçoada ou é o inverso da sociedade, mas, de qualquer forma, essas utopias são espaços que fundamentalmente são essencialmente irreais" (FOUCAULT, 1984/2009b, p. 414-415). Essa definição, presente em seu texto Outros espaços ${ }^{12}$, apresenta a utopia também como um espaço idealizado.

Se em As heterotopias (FOUCAULT, 1966/2013) o termo utopia remete à constituição de espaços irreais, em O corpo utópico (FOUCAULT, 1966/2010), o conceito é problematizado a partir do "pequeno fragmento de espaço" do qual o sujeito não consegue escapar: o próprio corpo. Se na primeira conferência o referido termo é contraposto à heterotopia, na segunda ele é posto em face de outro: topia. Diferentemente da utopia, que seria um "lugar fora de todos os lugares", o corpo é, a princípio, uma "topia implacável", um strictu corpus, que condena o indivíduo à sua indelével concretude (FOUCAULT, 1966/2010, p. 1). Foucault ilustra essa característica dialogando com o escritor francês Marcel Proust (18711922) e sua ideia de recuperação do corpo ao acordar. No primeiro volume de Em busca do tempo perdido: no caminho de Swan, Proust (2003, p. 10) descreve o adormecer como um processo de regresso "sem esforço a uma era para sempre passada [da] vida". Na volta desse processo de regresso, o corpo se faz presente e, por meio de seu próprio corpo, o sujeito se une a ele "e acorda" (PROUST, 2003, p. 10). O excerto exemplificativo demonstra uma abordagem que, de acordo com Foucault (1966/2010), é recorrente no pensamento de Proust, qual seja: a não separação entre sujeito e corpo. Ao contrário

\footnotetext{
${ }^{12}$ É importante mencionar que a noção de heterotopia do texto de 1967, embora possua aspectos semelhantes, não é exatamente a mesma da radioconferência de 1966. Enquanto em 1966 Foucault apresenta uma noção de heterotopia de forma mais ampla, que abarca tanto aspectos espaciais quanto biológicos e temporais, em 1967 o termo é utilizado para discutir questões arquiteturais, até porque o texto de 1967, que na verdade só foi publicado em 1984, é resultado de uma conferência proferida em 14 de março de 1967 para o Círculo de Estudos Arquitetônicos de Paris.
}

de uma utopia, o corpo, em seu aspecto tópico, “é o que nunca está sob outro céu, é o lugar absoluto, o pequeno fragmento de espaço com o qual, eu me corporizo" (PROUST, 2003, p. 1).

Assim como os espaços não são somente heterotopias, os corpos tampouco são somente topias. Dado seu caráter ambíguo, ou o fato de ser, ao mesmo tempo, coisa e vida, opacidade e transparência, visível e invisível, o corpo se fez, ao longo da história, utopia. Fez da "jaula desagradável", beleza, luz, transparência; fez-se, assim como os lugares irreais, corpo sem corpo, transfigurado, alheio, assim, à sua indelével concretude. Malgrado não se possa ignorar o papel da cultura na constituição utópica dos corpos, dissemos que o corpo "fez-se" utopia, porque "as utopias nasceram do próprio corpo", de sua estrutura lacunar, de sua própria opacidade e "talvez, depois, voltaram-se contra ele" (FOUCAULT, 1966/2010, p. 4).

Essa projeção irreal e ao mesmo tempo inerente à própria estrutura do corpo fez com que o aspecto tópico desse corpo restasse minimizado em nossa cultura. Como diz Foucault (1966/2010, p. 5): "Eis que meu corpo [em seu aspecto tópico] desapareceu". O resultado disso foi a produção de um corpo que está "sempre em outro lugar", num plano imaginário, num lugar que "é o além do mundo" (FOUCAULT, 1966/2010, p. 5-6). Como exemplos desses corpos idealizados, Foucault cita as múmias, que possuem um corpo transfigurado, que se estende através do tempo. Além destas, o filósofo também cita as estátuas, as pinturas, as esculturas; e termina por mencionar a mais poderosa de todas as utopias da história ocidental, capaz de relativizar a topologia do corpo: a alma. Esses elementos exemplificativos se tornaram utópicos porque foram expostos a uma cultura que retirou do corpo seu aspecto intrínseco, transpondo-o para um lugar vago, idealizado, mas também e principalmente porque, como dissemos, o próprio corpo, em razão de sua natureza dúbia, é o "grande ator" dessas utopias.

Mas não é apenas enquanto negação da concretude finita do corpo que age o seu caráter utópico, cuja possibilidade se encontra nele mesmo. Apesar dessa condição, esse corpo não é somente "pura e simples utopia" (FOUCAULT, 1966/2010, p. 6); a mesma ambiguidade que o torna o "grande ator utópico" também o torna suscetível a dobrar sobre si o mesmo movimento, de retornar sobre si mesmo o que o projeta para fora ou para outro lugar. Ou seja, ao mesmo tempo em que se sujeita a certas máscaras que o transfiguram e o idealizam, o corpo também pode voltar contra si seu próprio poder utópico. É justamente nesse movimento de dobra que ele experimenta seus próprios limites, que o faz entrar em "outro mundo", um "contra-mundo", justamente através do que lhe é mais próprio. Nos termos de Foucault (1966/2010, p. 5):

[...] é o próprio corpo que volta contra si seu poder utópico e faz entrar todo o espaço do religioso e do sagrado, todo o espaço do outro mundo, todo o espaço do contra-mundo, no interior mesmo do espaço que lhe está reservado. Então, o corpo, em sua materialidade, em sua carne, seria como o produto de suas próprias fantasias. Depois de tudo, acaso o corpo de um dançarino não é justamente um corpo dilatado segundo todo 
um espaço que lhe é interior e exterior ao mesmo tempo? E também os drogados, e os possuídos; os possuídos, cujo corpo se torna um inferno; os estigmatizados, cujo corpo se torna sofrimento, redenção e salvação, paraíso sangrento.

Ora, é nesse movimento de dobra do próprio corpo sobre si, que Foucault (1966/2010) destaca três experiências que o devolvem simplesmente à própria imanência, à sua mais pura contingência: as experiências do espelho, do cadáver e do amor. As visões que se tem do cadáver e de si mesmo no espelho se apresentam como experiências que devolvem o corpo à sua contingência mais crua, ao mesmo tempo inacessível e interdita. À contingência mais crua porque, no espelho ou no cadáver, o corpo se vê reduzido ao visível que é, e essa visão é capaz de "ocultar por um instante a utopia profunda e soberana de nosso corpo" (FOUCAULT, 1966/2010, p. 6). Um visível, no entanto, também inacessível e interdito, afinal, quem é esse que, enquanto corpo, se vê no espelho, cujo caráter expressivo por fim se apaga, como mostra a presença do cadáver? Ora, o amor, enquanto relação "física" com outro corpo, relação erótica ou "sexual" - que Foucault (1966/2010, p. 6-7) denomina "fazer amor"-, "assim como o espelho e como a morte, acalma a utopia do corpo, a cala, a fecha como numa caixa, a fecha e a sela". Sobre a especificidade do amor retornaremos a seguir. Por ora marquemos que são essas três experiências que Foucault (1966/2010) destaca como contrárias ao movimento utópico do corpo: eis que temos um corpo visível (no espelho), finito (que morre) e sensível (que ama). Um vidente que "é visível", uma vida "habitada pela morte", cujo sentido mais próprio é o "amor", ou ao menos, essa nos parece a sugestão deixada pela conferência de Foucault (1966/2010), que se encerra com o amor, como se esse, por fim, desvelasse o caminho ou a saída privilegiada pelo autor para a efetividade da vida, contrária à sua idealização utópica.

Em As heterotopias (FOUCAULT, 1966/2013), o espelho é tratado como um espaço misto, utópico e heterotópico, pois, ao mesmo tempo em que projeta a sombra num espaço irreal, devolve a visibilidade por meio de sua existência real (enquanto objeto). No caso de $O$ corpo utópico (FOUCAULT, 1966/2010), o espelho, ao projetar um corpo inacessível, não possibilita um reencontro com uma alma ou com uma função do eu, ao contrário, o corpo que projeta vê na impossibilidade do projetado sua imanência enquanto topia que fora retirada de si. De forma semelhante, o contato com o corpo morto, inerte, em forma de cadáver, expõe o indivíduo a um duplo movimento do limite: o primeiro advindo da constatação de que a própria vida possui um limite; o segundo, consequência do primeiro, a constatação de que, enquanto sujeito do conhecimento, o homem é limitado. Os contatos com o espelho e com o cadáver podem dar origem a experiências utópicas quando, através deles, o corpo se desdobra em lugares inalcançáveis; ainda privilegiados por Foucault (2010) porque, mesmo assim, só o fazem na medida em que através deles o corpo se vê impotente, limitado, finito, despojado momentaneamente de suas utopias. É "graças ao espelho e ao cadáver que nosso corpo não é pura e simples utopia" (FOUCAULT, 1966/2010, p. 6). Mas, além dessas duas experiências, há ainda uma terceira, exposta no final da conferência de 1966, que teria uma função semelhante: o amor. É importante ressaltar que nesse texto Foucault não fala de sexo ou sexualidade, mas de "amor" ou ainda "fazer amor" (1966/2010, p. 6). Paradoxalmente, se compreendermos a utopia como uma idealização, o próprio conceito de amor, em sua dimensão histórico-filosófica, pode ser considerado como uma utopia. Um exemplo disso está em O Banquete, de Platão (1991), no qual o amor seria apresentado por Sócrates $^{13}$ como uma forma de se aproximar daquilo que é "maravilhosamente belo em sua natureza": o belo em si (PLATÃO, 1991, p. 86). Diferentemente do discurso socrático apresentado por Platão (1991), Foucault não compreende o amor como uma busca pelo belo. Pode-se dizer que sua interpretação estaria mais próxima de Nietzsche (1885/2011) e Bataille (1944/1986) do que propriamente da abordagem clássica do platonismo. Em Nietzsche, as abordagens sobre o amor são muito variadas. Grosso modo, o pensador critica a ideia de amor como um princípio metafísico, eterno, capaz de conduzir ao belo. Quando falamos da aproximação foucaultiana com Nietzsche (1885/2011), nos referimos à obra Assim falou Zaratustra, na qual é possível observar a experiência do amor e da morte como experiências-limite. Segundo o personagem Zaratustra da obra de Nietzsche, amar e sucumbir são rimas desde a eternidade. "Vontade de amor: isto é, estar disposto também para a morte" (NIETZSCHE, 1885/2011, p. 224). No trecho, a "morte" se refere ao homem e a todas as suas limitações metafísicas; a "vontade de amor" estaria próxima de uma vontade de potência, desejo de desvio, de estar próximo do limite. Em Foucault (1966/2010), o amor também estaria próximo da experiência da morte e, portanto, próximo de um limite às utopias do corpo; contudo, neste caso, seu objetivo não é produzir uma vontade de desgarrar-se de si, mas de dobrar-se enquanto corpo, enquanto vida. Essa dobra do corpo se dá principalmente por meio do contato com o outro. É "entre as mãos do outro" que o corpo pode "fechar sobre si" e "existir fora de toda utopia"; [é] "sob os dedos do outro que... todas as partes invisíveis do corpo se põem a existir, [é] contra os lábios do outro [que] os teus se tornam sensíveis, diante de seus olhos semi-abertos teu rosto adquire uma certeza, há um olhar finalmente para ver tuas pálpebras fechadas" (FOUCAULT, 1966/2010, p. 6). Há nesse trecho uma proximidade com o pensamento de Bataille. De acordo com Machado (2005, p. 61), “os conceitos de limite e transgressão são utilizados por Bataille (1986) para pensar o erotismo como exuberância da vida, como promessa de vida, como ápice da vida" [e nesse sentido] o erotismo seria um "domínio de transgressão", "uma vitória sobre o interdito", "uma atividade sexual [...] que liga o prazer à transgressão". Foucault (2010, p. 6), por sua vez, não ${ }^{13}$ Em O Banquete, de Platão (1991), ao tratar do amor, Sócrates retoma um diálogo que julga importante para seu entendimento acerca do tema: trata-se do diálogo com Diotima, uma mulher estrangeira proveniente da região grega da Mantinéia. Em certo momento do diálogo, Diotima enuncia que aquele "que tiver sido orientado para as coisas do amor, contemplando [...] corretamente o que é belo, já chegando ao ápice dos graus do amor, súbito perceberá algo de maravilhosamente belo em sua natureza, aquilo mesmo" (PLATÃO, 1991, p. 86). 
fala em sexo, mas em "amor", em "fazer amor". Parece evidente que este amor, ao qual o autor se refere, não seria aquele proveniente do platonismo, mas algo próximo do erotismo de Bataille (1944/1986). Talvez a diferença entre eles esteja no fato de que a conferência não pretende apresentar experiências-limite como um projeto de dessubjetivação, tal como Foucault (2001) sugere na entrevista de 1978. O termo "sujeito" sequer aparece na rádioconferência de 1966; o que importa é o corpo, sua possibilidade de apresentar experiências que transgridam as utopias que lhe são impostas. E se Foucault (2010) termina a conferência com o amor é porque, nos parece, escolhe a vida e não a morte (cadáver), ou escolhe a imanência da vida na sua experiência mais concreta, porque, ao contrário da imagem (espelho), dá-se no encontro com outro corpo, numa experiência na qual o outro lhe devolve àquilo que lhe é mais próprio, à própria contingência para a sua experiência, isto é, de seus limites, que se apoia, pois, na possibilidade de sua transgressão, ou ainda, no advento do acontecimento histórico, em sua dimensão descontínua do tempo. Não se trata, então, de nova versão utópica a invadi-lo e transfigurar a própria carne e a fazer do corpo mais um "produto de suas próprias fantasias", porque se trata da imanência na experiência entre os corpos que se amam. É aí que tudo se passa, numa história que, em tese, seria contrária a toda idealização, isto é, efetividade pura enquanto experiência de sentido imanente à vida da própria relação entre os corpos.

\section{Conclusão}

Além de apresentar um material pouco explorado por analistas da obra de Michel Foucault, o presente trabalho objetivou mostrar como a noção de "limite" (FOUCAULT, 2001, p. 862) pode adquirir significações distintas em textos que figuram fora da "tríade canônica" da obra foucaultiana, a saber: um ensaio proferido em uma rádioconferência, um texto homenagem a George Bataille, ambos da década de 1960, e uma entrevista concedida no final da década de 1970 . No caso específico da conferência de 1966, o que se pôde constatar é que a lógica da transfiguração ou transvaloração do sujeito, apresentada por Foucault na entrevista de 1978 como uma importante característica da experiência-limite, dá-se a partir do corpo. Dito de modo mais específico, em $O$ corpo utópico (FOUCAULT, 1966/2010) questionam-se os espaços irreais a que o corpo fora submetido ao longo da história. O ponto-limite torna-se possível a partir do momento em que o corpo volta contra si sua utopia e, por meio de experiências com o espelho, a morte e o amor, vê-se momentaneamente como matéria frágil, topia que fora retirada de si, topia implacável. O que essa dobra do corpo por fim revela é também um limite que advém da própria efetividade da vida, isto é, para que enfrente sua opacidade, o corpo não necessita desdobrar-se em utopia, basta que dobre em si mesmo, implacável como topia, imanente à própria vida, para que seja, pois, experiência-limite.

\section{Informações sobre os autores:}

Mauricio Silva

(iD) https://orcid.org/0000-0002-9294-0352

(9) http://lattes.cnpq.br/0842300421759043

Doutor em Linguística pela Faculdade de Ciências e Letras de Araraquara - UNESP (2015). Doutor em Ciências (Programa de Psicologia) pela Faculdade de Filosofia, Ciências e Letras de Ribeirão Preto - USP (2015). Mestre em Linguística pela Universidade de Franca (2010). Graduado em História pela Faculdade de História, Direito e Serviço Social - UNESP (2005). Graduado em Direito pela Faculdade de Direito de Franca (2010).

Reinaldo Furlan

(iD) https://orcid.org/0000-0003-2117-3886

(9) http://lattes.cnpq.br/7492093482568386

Possui graduação em Licenciatura Plena em Filosofia pela Pontifícia Universidade Católica de Campinas (1982), mestrado em Filosofia pela Universidade Federal de São Carlos (1993) e doutorado em Filosofia pela Universidade Estadual de Campinas (1997). Realizou estágio de pós-doutoramento na Universidade Jean Moulin, Lyon 3, França (2013-2014), com bolsa Fapesp e colaboração de Étienne Bimbenet.

\section{Contribuições dos autores:}

Mauricio Silva foi responsável pela concepção, desenho, análise, interpretação dos dados, revisão e aprovação da versão final do artigo. Reinaldo Furlan participou da concepção, desenho, análise, interpretação dos dados, revisão e aprovação da versão final do artigo.

\section{Como citar este artigo:}

\section{ABNT}

SILVA, Mauricio; FURLAN, Reinaldo. Corpo, utopia e limite no pensamento de Michel Foucault. Fractal: Revista de Psicologia, Niterói, v. 31, n. 2, p. 111-118, maio/ago. 2019. https://doi. org/10.22409/1984-0292/v31i2/5629

\section{APA}

Silva, M., \& Furlan, R. (2019). Corpo, utopia e limite no pensamento de Michel Foucault. Fractal: Revista de Psicologia, 31(2), 111-118. doi:10.22409/1984-0292/v31i2/5629

\section{Referências}

BATAILLE, Georges. La experiência interior (1944). Tradução de Fernando Savater. Madrid: Taurus, 1986.

BIMBENET, Étienne. Comme à la limite de la mer un visage de sable: Merleau-Ponty et Foucault. In: Après Merleau-

Ponty: études sur la fécondité d'une pensée. Paris: Librairie Philosophique J. Vrin, 2011. p. 15-42.

CHAUÍ, Marilena. Notas sobre Utopia. Ciência e Cultura, São Paulo, v. 60, n. spe1, p. 7-12, 2008. Disponível em: http://cienciaecultura.bvs.br/scielo.php?script=sci arttext\&pid=S0009-67252008000500003\&lng=en\&nrm=iso. Acesso em: 22 mar. 2016.

DELEUZE, Gilles. Foucault. (Martins, C.S.A.; trad.). São Paulo: Brasiliense, 1988.

FOUCAULT, Michel. De los espacios otros. Conferencia dicada en el Cercle des études architecturals, 14 de marzo de 1967. Tradução de Pablo Blitstein y Tadeo Lima. Disponível em: $\quad$ http://disciplinas.stoa.usp.br/mod/resource/view. php?id=67995. Acesso em: 5 abr. 2016.

FOUCAULT, Michel. Doença mental e psicologia (1962). Tradução de Lilian Rose Shalders. Rio de Janeiro: Tempo Brasileiro, 1975. 
FOUCAULT, Michel. A história da loucura na idade clássica (1961). Tradução de José Teixeira Coelho Netto. São Paulo: Perspectiva, 1978.

FOUCAULT, Michel. Préface à la transgression, Critique, n. 195-196: Hommage à G. Bataille (1963). In:

Dits et ecrits (1954-1988), tome I: 1954-1969. Paris: Quarto Gallimard, 1994. p. 233-250.

FOUCAULT, Michel. La pensée du dehors, Critique, n. 229 (1966). In: . Dits et ecrits (1954-1988), tome I: 1954-

1969. Paris: Quarto Gallimard, 1994. p. 518-539.

FOUCAULT, Michel. História da sexualidade: a vontade de saber (1976). Tradução de Maria Thereza da Costa Albuquerque e J. A. Guilhon Albuquerque. 13. ed. Rio de Janeiro: Graal, 1999. v. 1.

FOUCAULT, Michel. As palavras e as coisas (1966). Tradução de Salma Tannus Muchail. São Paulo: Martins Fontes, 2000.

FOUCAULT, Michel. Dits et ecrits II: 1976-1988 (1994). Paris: Quarto Gallimard, 2001.

FOUCAULT, Michel. El poder psiquiátrico: curso en el Collège de France. (Pons, H., trad.). Buenos Aires: Fondo de Cultura Economica de Argentina, 2003.

FOUCAULT, Michel. Vigiar e punir: nascimento da prisão (1975). 35. ed. Petrópolis, RJ: Vozes, 2008.

FOUCAULT, Michel. A arqueologia do saber (1969). Tradução de Luiz Felipe Baeta Neves. 7. ed. Rio de Janeiro: Forense Universitária, 2009a.

FOUCAULT, Michel. (1984). Outros espaços. In: MOTTA, Manoel Barros (Org.). Estética: literatura e pintura, música e cinema. Tradução de Inês Dourado Barbosa. Rio de Janeiro: Forense Universitária, 2009b. Coleção Ditos \& Escritos, v. 3, p. 411-422.

FOUCAULT, Michel. O corpo utópico: texto inédito de Michel Foucault (1966/2010). Disponível em: https://www.geledes. org.br/cansada-de-ler-sobre-garotos-menina-reune-4-000livros-com-garotas-negras/. Acesso em: 17 set. 2013.

FOUCAULT, Michel. O corpo utópico: as heterotopias. (1966). Tradução de Salma Tannus Muchail. São Paulo: Edições n-1, 2013.

MACHADO, Roberto. Foucault, a filosofia e a literatura. 3. ed.. Rio de Janeiro: J. Zahar, 2005.

NIETZSCHE, Friedrich. Assim falou Zaratustra: um livro para todos e para ninguém (1885). Tradução de Paulo César de Souza. São Paulo: Companhia das Letras, 2011.

NIETZSCHE, Friedrich. A gaia ciência (1882). Tradução de Antônio Carlos Braga. São Paulo: Escala, 2006. Coleção Grandes Obras do Pensamento Universal.

PLATÃO. Diálogos. Os pensadores. Tradução de José Cavalcante de Souza, Jorge Paleikat e João Cruz Costa. 5. ed. São Paulo: Nova Cultural, 1991.

PROUST, Marcel. No caminho de Swan. Tradução de Fernando Py. São Paulo: Folha de São Paulo, 2003. Coleção Em Busca do Tempo Perdido, v. 1.

SABOT, Philippe. Langage, société, corps : utopies et hétérotopies chez Michel Foucault, 2012. Disponível em: https://halshs.archives-ouvertes.fr/halshs-00746742/document. Acesso em: 4 maio 2016. 